\title{
Ocular Surface as Barrier of Innate Immunity
}

\author{
Rodrigo Bolaños-Jiménez ${ }^{*}, 1,2$, Alejandro Navas ${ }^{1,3}$, Erika Paulina López-Lizárraga ${ }^{3}$, \\ Francesc March de Ribot ${ }^{4}$, Alexandra Peña ${ }^{2}$, Enrique O. Graue-Hernández ${ }^{1,3}$ and \\ Yonathan Garfias ${ }^{1,5}$
}

\author{
${ }^{1}$ Research Unit, Institute of Ophthalmology, Conde de Valenciana Foundation, Chimalpopoca 14, Obrera, CP 06800, \\ Mexico City, México \\ ${ }^{2}$ Ophthalmology Department, Regional Hospital, Adolfo López Mateos, ISSSTE, México City, México \\ ${ }^{3}$ Department of Cataract and refractive surgery, Institute of Ophthalmology, Conde de Valenciana Foundation, Mexico \\ City, México \\ ${ }^{4}$ Department of Retina, Institute of Ophthalmology, Conde de Valenciana Foundation, Mexico City, México \\ 5 Department of Biochemistry, Faculty of Medicine, Universidad Nacional Autónoma de México, 04510. Mexico City, \\ Mexico
}

\begin{abstract}
Sight is one of the most important senses that human beings possess. The ocular system is a complex structure equipped with mechanisms that prevent or limit damage caused by physical, chemical, infectious and environmental factors. These mechanisms include a series of anatomical, cellular and humoral factors that have been a matter of study. The cornea is not only the most powerful and important lens of the optical system, but also, it has been involved in many other physiological and pathological processes apart from its refractive nature; the morphological and histological properties of the cornea have been thoroughly studied for the last fifty years; drawing attention in its molecular characteristics of immune response. This paper will review the anatomical and physiological aspects of the cornea, conjunctiva and lacrimal apparatus, as well as the innate immunity at the ocular surface.
\end{abstract}

Keywords: Cornea, innate immunity, mucins, neuropeptides, ocular surface, pattern recognition receptors.

\section{INTRODUCTION}

In order to eliminate a pathogen, the immune system must recognize it and develop and adequate response to destroy it. The immune system has two types of mechanisms: innate and adaptive immunity. The innate immunitys strategy consists of recognizing a group of molecular patterns common to an entire family of pathogens. ${ }^{1}$ Thus, all individuals within one species are born with innate ability to recognize and destroy numerous microorganisms immediately. Innate immunity is, therefore, able to fight infections from the beginning and during early stages with high efficiency (about 0-5 days). If these mechanisms fail to eliminate the infection, they at least at least they keep it under control until other mechanisms take place [1]. The first and most basic defense mechanism against infection are epithelia and mucous membranes, which are mechanical, chemical (defensins, lysozyme) and biological barriers against pathogens [2]. If microorganisms are able to cross these barriers and establish an infection, there are two pre-existing innate mechanisms that act

*Address correspondence to this author at the Research Unit, Institute of Ophthalmology Chimalpopoca 14, Obrera, 06800 Mexico City, Mexico; Tel: +52(55) 54421700, Ext. 3212; Fax: +52(55) 54421700,

Ext.3206; E-mail: rodrigoboji88@gmail.com immediately: humoral and cell - mediated immunity. Humoral immunity is mediated by macromolecules (as opposed to cell-mediated immunity) such as antibodies, complement proteins and certain antimicrobial peptides. Cell -mediated immuntity involves the activation of phagocytes, antigen-specific cytotoxic T-lymphocytes, and the release of various cytokines in response to an antigen [3]. All cells of the immune system need to be closely related to each other to develop a coordinated immune response that culminates in the elimination of the pathogen. Cells use two main ways to communicate: by direct contact with membrane molecules, and through cytokines synthesis. Many of the cytokines are produced in the first moment of cell activation, alerting cells with cytokine membrane receptors. Cytokines are molecules that often have only a local effect, taking part in antigen recognition and distance response, cytokines participate in regulation of the length and intensity of the innate and specific immune response, recruiting cells towards the conflict zone and inducing the generation of new cells from hematopoietic precursors [4]. Cytokines share functions with the so called host defense peptides (HDPs), proteins that act as effector molecules of innate immunity [5]. The cornea, as the outmost part of the eye, is constantly exposed to various agents potentially harmful to its surface and the internal structures of the eye, the reason why is endowed with various elements of innate and adaptive immunity, and is 
sheltered by anatomical structures, conjunctiva, and lacrimal system. The following will describe this in greater detail.

\section{OCULAR SURFACE ANATOMY}

\section{Cornea}

The epithelium is the external layer of the cornea with approximately $50 \mu \mathrm{m}$ thickness, underneath is Bowman's layer which is $10 \mu \mathrm{m}$ thick, stroma $480 \mu \mathrm{m}$ thick in the center and $900 \mu \mathrm{m}$ thick in the periphery, Dua's layer (recognized by some researchers) which is hypothetically $15 \mu \mathrm{m}$ thick, Descemet's membrane $12 \mu \mathrm{m}$ thick and at the most inner level the endothelial cells with a 4-6 $\mu \mathrm{m}$ thickness $[6,7]$.

The cornea has the highest dioptric power of the optical complex due to its prolate shape where the central $4 \mathrm{~mm}$ tends to be spherical, but then gradually flattens toward the periphery $[6,8]$; The rigidity of the stroma contributes to keep the shape and its refractive properties [9]. In order to be transparent the cornea needs to be avascular, receiving its nutrients through diffusion from the tear film and through aqueous humor [10,11]. The cornea is one of the body structures most densely innervated, the innervations comes from axons of the sympathetic ganglion and trigeminal ganglion [10]. Corneal nerve fibers and associated neurotrophins, influences on the corneal epithelium and contribute to the maintenance of a healthy ocular surface.

The corneal epithelium is a stratified, non-keratinized squamous layer [12]. It has three types of cells: The most external type of cells are the superficial epithelial cells, in the middle are the wing cells located on top of the inner layer which are the basal epithelial cells [6]. Due to its histological nature, the epithelium has the primary function of providing a barrier to the cornea and the rest of the eyeball [7]. Also important, the tear film contributes to the refractive and barrier function. An important characteristic of this epithelium is waterproof property, because the epithelium provides additional protection against water-soluble substances that could alter the refractive properties and/or intraocular environment [13]. Interestingly, the corneal epithelium has also an anti-angiogenic function, preventing blood vessels from proliferation and subsequent loss of corneal transparency [14]. Basal cells are in charge of regenerating loss of integrity of superficial layers [15]. They detach from the basal lamina and progressively replace the winged and superficial epithelial cells, which are displaced anteriorly and are eventually desquamated. They are tightly attached to the underlying basement membrane, which allows the epithelium to remain bound to the underneath cells.

Underneath the epithelial basal membrane layer of the cornea, lies the Bowman's layer. This layer has no structures in it. It is composed of thin, type I, III, V and VI collagen microfibrils. It is not an independent membrane, but a modification of the most superficial portion of the stroma of the cornea [7]. The stroma represents the main support of the corneal structure and comprises up to $90 \%$ of its volume. This compartment is about $450 \mu \mathrm{m}$ thick and it contains nerves of variable size, stromal keratocytes with different morphology and type I and V collagen fibers $[16,17]$. The nerves are located in the anterior stroma, just below the
Bowman's layer, where they form the subepithelial nerve plexus [18]. Keratan sulfate is part of the most abundant proteoglycans in the cornea, there are also chondroitin sulfate and dermatan sufate. Proteoglycans contribute to the structural function of the stroma.

These molecules are synthesized by the stromal keratocytes, which also produce matrix metalloproteases to maintain the homeostasis of the stroma [19]. As neighboring layers, there are a series of interactions between the stroma and the epithelium, where the keratocytes from one layer produce cytokines to modulate the functions of keratocytes of the other layer [20]. Dua's layer is a strong acellular layer in the pre-Descemet's cornea, made of 5 to 8 thin lamellae of tightly packed type I, VI, and VI collagen bundles running in longitudinal, transverse, and oblique directions [21]. This structure is capable of supporting up to 2 bars of pressure. The Descemet's membrane, like the Bowman's layer, has no structures in it. It represents the basal membrane of the posterior epithelium and is secreted by them. It is formed by very thin filaments of type IV collagen, which are arranged in a very regular pattern. The endothelium is a monolayer of cells that aids in keeping the corneal transparency not only by its barrier function, but also by its ionic pump function [22]. Primarily in the basolateral membrane of endothelial cell, there are sites for the $\mathrm{Na}+/ \mathrm{K}+$ - ATPase pump, contributing to corneal transparency [23-25]. It is important to consider that contrary to the epithelium, endothelial cells are not replaced with ageing or severe damage. Endotelial cells decrease their barrier and pump function over time, sometimes resulting in corneal edema and visual loss [26]. Additionally the endothelium has the function of providing the upper layers with nutrients coming from the aqueous humor, thus serving as a semipermeable membrane that selectively allows passage of glucose and other small molecules to the stroma [27]. This semipermeable property is also used to maintain the water balance of the stroma [28]. For this function, the integrity of the tight and adherent junctions between the endothelial cells is required [29]. For there to be fluid movement from one chamber to another, as in the rest of the body, there must be an osmotic gradient. Compared with the aqueous humor, which is hypertonic, the stroma is hypotonic. This difference in osmolarity is generated by $\mathrm{Na}+/ \mathrm{K}+-\mathrm{ATPase}$ pumps, and it is maintained by the semipermeability of the endothelium to ion flux, to set up the osmotic gradient [30]. It has also been recently demostrated that aquaporin water channels, more specifically AQP1, are expressed in the corneal endothelial cells to contribute to transcelular fluid flow [31].

\section{THE TEAR FILM AND BIOCHEMISTRY}

The tear film covers the ocular surface, and provides major refractive power of the visual system [32]. Other functions of the tear film include nutrition of the ocular surface, lubrication and a chemical barrier [33]. It forms a thin film layer of $8 \mu \mathrm{m}$ thick; Although is typically said that is formed of three layers; the external or lipid layer, the central or aqueous layer and the inner or mucin layer, It is now recognized that the tear film is more a lipid boundary layer with aqueous phases incorporating differing concentrations of mucins throughout. Meibomian and Moll glands produce the lipid component [34], mainly wax esters, 
triglycerides, free fatty acids, as well as neutral diesters [35]. Lacrimal glands produce the aqueous component and goblet cells which are located in the conjunctiva, secrets the mucin and contains membrane associated glycoproteins [36]. Other components of the tear film are metabolites and electrolytes [37]. Interestingly, the proteins contained in the tear film take part in other processes, for instance, they work as antimicrobials, anti-inflammatories and also help in healing processes after trauma, as well as mechanical protection to the surface of the cornea [38]. Tears also transport carbon dioxide and oxygen, taking part the in ocular surface metabolism [39]. The meibomian glands are present in both the upper and lower lids in the tarsal plate and they are composed of many acini, formed by cells which secrete unique meibomian gland lipids, such as cholesterol, wax and cholesterol esters, which all the latter form part of the nonpolar lipids, and account for $65 \%$ of the tear film lipids, as well as polar lipids (phospholipids and glycolipids) [40]. These substances are then excreted onto the ocular surface on the lid margin, where the mucocutaneous junction is located [41]. As mentioned, lacrimal glands are responsible of synthesizing the aqueous portion of the tear film. The main gland (orbital and palpebral portion) produces the reflex tear secretion onto the supero-lateral portion of the fornix, as well as accessory lacrimal glands produce the basal portion of the lacrimal film on the upper fornix [42]. The aqueous component accounts for $60 \%$ of the tear and it mainly contains water, electrolytes and proteins [43]. There have been identified dozens of different proteins contained in the tear, but the three main ones are: lysozyme, lactoferrin and tear-specific prealbumin (lipocalin) [44]. The lysozyme is an enzyme with antimicrobial function, as it destroys the glycosidic bonds between peptidoglycans in bacteria cell wall [45]. Lactoferrin protects the ocular surface from the effects of free radicals. The role of the lipocalins has not been clearly demonstrated, but they may have more than one function in the tear film; depurating the ocular surface from hazardous substances or aiding to spread the lipids on the tear film [46].

Mucins are hydrophilic glycoproteins which carbohydrate mass is of approximately $50-80 \%$, Residues that are O-linked to serine and threonine, have in their protein backbone tandem amino acid repeats [47]. On the ocular surface, mucins can be associated with glycocalyx of conjunctival and corneal epithelium or with a mucous layer produced by the goblet cells [36]. The glycocalyx is a carbohydrate- based cover found on the surface of epithelia, to where mucous layers can get attached [48]. Mucins in the eye have multiple functions; by themselves, mucins lubricate the eye, indirectly they protect the epithelium from drying as they prevent tears from evaporating, they serve as another protective barrier against the hostile environment, they secure the aqueous layer of the tear film to the ocular surface, they protect from microbial invasion of the epithelium as they serve as a platform to hold other antimicrobial proteins to the eye $[49,50]$. Depending on the structure of their molecule, mucins can be of two different kinds; secreted or cell- surface associated mucins. Goblet cells are in charge of the synthesis of secreted mucins and of the properties of the mucous as well, while the membranespanning mucins have more to do with structural function [52]. Within the secreted mucins, two types can be identified, large gel-forming mucins and smaller nonpolymeric mucins. The main gel-forming mucin at the ocular surface is MUC5AC, which is localized in the goblet cells of the conjunctiva, whereas the nonpolymeric mucin MUC7 can be found in acinar cells of the lacrimal gland [51].

MUC1, MUC4 and MUC16 are examples of mucins expressed in the corneal and conjunctival epithelia. Other mucins such as MUC1, MUC2, MUC4, MUC5AC and MUC16, have been found in the tear film [47].

\section{OCULAR SURFACE INNATE IMMUNITY}

The term ocular surface is often employed in order to describe the assembly conformed by the cornea, the conjunctiva and the tear film which help maintaining visual acuity and also present interesting biochemical interactions that allow them to work as an immunological unit capable to respond to internal and external stimuli as well as modulating those responses in order to avoid exaggerated or chronic reactions [52]. Innate immunity provides a nonspecific surveillance system against corneal infection and is able to be the first form of protection, during the first minutes or hours, when the infection presents.

The ocular surface is formed by a variety of anatomical and functional components that include the bony orbit, eyelids, tears, corneal nerves, the corneal epithelium, leukocytes and cytokines [53,54]. The bony orbit and eyelids comprise the main anatomical structures that provide protection to the ocular surface, specially against traumatic events. Tears are secretions with the main function of lubricating and preventing the cornea from drying, flushing away foreign particles from the ocular surface, as well as distributing immunoglobulins ( $\operatorname{IgA}$ and $\operatorname{IgG}$ ) and antimicrobial proteins (lactoferrin, lysozyme, lipocalin and beta-lysin) to the ocular surface in order to prevent infections [55]. Cell-cell junctions of corneal and conjunctival epithelia complete the first line of anatomical barriers in the eye [56]. The corneal' s innate immune system is comprised by many types of cells including epithelial cells, fibroblasts and Langerhan's cells. Epithelial cells are in charge of the secretion of TNF- $\alpha$, IL-1, IL- 6 and IL-8.

Fibroblasts in the stroma may be in charge of the production of IL-1, IL- 6 , IL- 8 , TNF- $\alpha$, and $\alpha$-defensin as a way of after microbial infections; in addition, Langerhans cells in the cornea and conjunctiva are in charge of the adjustment of the $\mathrm{B}$ and $\mathrm{T}$ lymphocyte activity of the adaptive immunological response [53,57]. Toll- like receptors (TLR) are a group of fundamental molecules for the development of the innate immune response; so far 13 types of TLR have been recognized, TLRs 1 to 10 are present in humans, while TLRs 11 to 13 are unique to mice [58-60]. TLRs have extracellular and intracellular domains. The extracellular domain contains repeats that are rich in leucine (LRR: leucine-rich plates) while the intracellular domain is equivalent to the receptor of IL-1 (IL-1R: IL-1 receptor), and it may be named as the TIR: toll/il-1R domain [61].

Through the recognition of pathogen-associated molecular patterns (PAMPs), Toll like receptors are able to unleash immune responses. Structures that are preserved 
across the microorganisms of a given class and are vital for their survival, have become a great place of detection by the innate immune system since they enable a quick way to differentiate between non-self and self [60]. TLRs can be broadly divided by their location (intra or extracellular), or by the type of ligands they recognize (cell wall or genetic material) [54].

TLR2's main function is to form heterodimers with TLR6 or TLR1 in order to recognize ligands from bacteria; TLR1/TLR2 heterodimers are able to recognize bacterial lipopeptides, including mycobacterial lipoprotein, meningococcal lipoproteins and triacylated lipoproteins [6265]; TLR2/TLR6 heterodimer are able to recognize mycoplasma lipoproteins and peptidoglycan [66]; TLR2 can also act as an homodimer for the recognition of Grampositive cell walls, lipotheicoic acid, mycobacterial lipoarabinomannan, zymosan and heat-shock protein $[60,54,67,68]$. TLR2 has also been suggested to be a Staphylococcus aureus innate receptor, functioning as a detector of Gram-positive bacterias in the cornea [64].

TLR4 is expressed in corneal and conjunctival cells, fibroblasts and dendritic cells; it is able to form complexes with CD14 and MD2 for the recognition of lipopolysaccaride (LPS) from Gram- negative bacteria cell walls [69]; its function requires several co- receptors, like MD2 and CD14 [65]. Unnecesary proinflammatory reactions due to the presence of commensal bacteria on the corneal surface are avoided by expressing minimal levels of TLR4 on the apical cells and the absence of MD2, one of the main co-receptors of TLR4 [66]. TLR5 is able to recognize flagellin, a major protein present in bacterial flagella [70]; it is a major sensor for the detection of bacteria that is Gram- negative and activates signalign pathways that liberate NF-kB and activate pro-inflammatory genes $[71,72]$.

TLR5 are expressed on the surface of wing and basal corneal cells, different from superficial epithelial cells that do not express TLR5. Therefore, its activation only occurs when the barrier function of the cornea is compromised [70]. TLR3 is expressed by surface epithelial cells, where it acts as a receptor for viral double-strained RNA (dsRNA) [73], poly I:C and an analog of dsRNA [74]. Upon TLR3 stimulation NF-kB is activated, with the secretion of IL-6, IL-8, indicating that TLR3 is capable of unleashing an antiviral response.73 TLR7 and TLR8 have been implicated in the recognition of viral PAMPs, specifically singlestranded RNA (ssRNA), causing the virus infected macrophages to produce IFN- $\alpha$ and dendritic cells $[54,75]$. TLR9 is located in intracellular endosomal compartments, and specializes in the recognition of DNA with unmethylated $\mathrm{CpG}$ motifs from bacterial and viral genomes [76]. Activation of TLR9 induces a Th1 response with secretion of IL- 1277 IL-18 [54, 76, 77]. TLR activation leads to immune cell recruitment, cytokine release and the modulation of corneal healing. Activation of TLR pathways induces the specific expression of cytokines, and MHC molecules, helping an immune adaptive response to take place [78]. TLRs have several pathways: common adaptor molecule that is the primary-response protein 88 of myeloid differentiation (MyD88), TIR domain that comprises adaptor protein (this latter may also be known as TIRAP, MyD88-adaptor-like protein, or MAL), TIR-domain that has an adaptor that induces interferon $\beta$ (also known as TIR-domain-containingadaptor molecule 1, TICAM-1, or TRIF), and the molecule that is associated to the TRIF-related-adaptor (also known as TIR- domain-containing-adaptor molecule 2, TRAM or TICAM-2) [79].

The above have been described as the adaptor molecules, after this, the downstring signaling pathways are divided into MyD88-dependent and MyD88-non dependent. In order to produce signaling by TLR2 and TLR4, MyD88- dependent signaling is needed. This latter subsequently activates NF-kB $[80,81]$; For the induction of IFN- $\beta$, TRIF works through the via of TLR3 and TLR4 MyD88-independent pathway [82].

The signaling pathway known as MyD88independent/TRIF-dependent, is associated with activation by TRAM, and this takes places with the help of TLR4 that subsequently causes genes that are induced by IFN to express [83]. In order to have an adequate ligation of their PAMPs, receptors that are not related to TLR, for example MD2 and CD14 are used by TLRs. After the binding of this ligand, conformational adjustments take place with the purpose of enrolling downstream molecules for signaling.

The domain that is present in the C-terminus of MyD88, interacts with a TIR-domain and this causes the TLRs to recruit MyD88 which is the adapter molecule, and all of this as part of the MyD88- dependent pathway [84,85].

Through the death domain communication, the TLR complex receives through recruitment by MyD88, the IL-1R associated kinase (IRAK) and IRAK-4. Association of MyD88 to IRAK and IRAK, causes their phosphorylation and subsequent activation. Once IRAK is phosphorylated, it then separates from MyD88, and binds with the tumor necrosis factor receptor- associated factor 6 (TRAF6) [86]. Then, the TRAF6-IRAK complex binds to the TGF- $\beta$ activated protein kinase (TAK-1), which is associated with the TAK-1 binding proteins: TAB-1 and TAB-2. All these pathways trigger secondarily phosphorylation and activation of TAK1 [85].

As a result, the NF-kB-dependent transcription factor is activated after TAK1 once activated as well, phosphorylates the inhibitor of the NF-kB (IkB)- kinase (IKK) complex. This latter consists of IKKa, IKKb and NF-kB essential modulator (NEMO)/IKKg. TAK 1 can also causes the mitogen-activated protein and the stress associated protein to activate kinases (MAP and SAP respectively), for example: extracellular signal-related kinase (ERK), Jun N-terminal kinase (JNK) and p38. Pro inflammatory molecules such as IL-6, IL-8, IL-18, MIP-1 and TNF- $\alpha$ are produced secondarily after NF-kB is activated.

The transcription factor IFN regulatory factor 3 (IRF3) is phosphorylated due to activity of the MyD88-independent signaling. IFN- $\beta$ type I is formed when phosphorylated IRF3 is translocated to the nucleus and activates its production. The production of IFN- $\beta$ type I induces more production of IFN- $\alpha$, IFN $-\beta$ and the expression of IRF7 $[85,87]$.

Despite its capability to produce and release proinflammatory cytokines, the ocular surface is also in constant contact with its comensal bacteria, mainly Staphilococcus epidermidis and Propionibacterium acnes, 88 which guides us to believe there must be negatively 
regulatory pathways for innate immunity, since a chronic inflammatory response in the cornea would lead to scarring and loss of visual acuity. Several molecules have been proposed to act as counter regulators, including MyD88 short, SIGIRR, Tollip, and ST2 [54]. These molecules confer the ocular surface unique characteristics that may contribute to the coexistence of comensal bacteria and TLRs [88]. Complete elimination of the offending microorganisms can only be achieved by the induction of adaptive immunity. TLRs initiate the inflammatory cascade by recruiting innate inflammatory cells to the sites of infection, like PMNs and NK lymphocytes; afterwards the arrival of monocytes and dendritic cells will initiate the adaptive immune response by capturing foreign antigens and presenting them to naive $\mathrm{T}$ lymphocytes by expressing MHC molecules [89, 90]. TLR agonists have proven to be effective for the treatment of some allergic, immunologic and infectious diseases in the ocular surface, TLRs are increasingly becoming therapeutic targets for the modulation of inflammation in the ocular surface, avoiding or becoming alternatives to broadly employed anti- inflammatories like corticosteroids [57]. The cornea can be considered an immune privileged tissue, a term developed in order to explain the high success rate of corneal transplantation [91]. This situation was at first explained by the lack of vasculature and lymphatic drainage in the cornea, resulting in a delay in the traffic of antigen presenting cells (APC) to lymphatic nodes, and the barrier the lack of vasculature represents for effector cells. However, recent research has revealed the process to be more complex and active, rather than passive; diverse endocrine, neural and immunological factors are essential for the preservation of the ocular surface and normal visual function [52]. Local and systemical modulation is necessary to maintain immunological homeostasis. Intraocular regulation is achieved in part due to the pigmented epithelial cells of the iris by producing immunosuppresive molecules like CD86, PD-L1 and CTLA-2 $\alpha$, that are capable of inducing Tregs. Pigmented cells also release TGF $\beta$, an immunoregulatory cytokine, antigen presenting cells in the ocular tissue are exposed to it and generate antigen-specific Tregs that migrate to the spleen and establish immune tolerance to those antigens, this process is known as anterior chamber immune deviation (ACAID) [92]. Neural pathways also have an important paper in inducing inflammatory response. Presence of neuropeptides inside the aqueous humor possesses immunoregulatory characteristics, while the presence of sensory and sympathetic nerve fibers in the cornea allows the maintenance of ocular immune privilege by increasing the le vels of TGFß [93]. Some authors have proposed that parasympathetic nerve fibers could also have an important paper on the ocular surface immunoregulation by increasing the levels of VIP and somatostatin [94].

\section{CONCLUSION}

There are many studies indicating that a myriad of molecules such as neuropeptides, mucins, pattern recognition receptors, among others are involved in the very complex immune system of the ocular surface just described. Taken together these results, reinforce the idea that the ocular surface is a versatile epithelial barrier.

\section{CONFLICT OF INTEREST}

The authors confirm that this article content has no conflict of interest.

\section{ACKNOWLEDGEMENTS}

Declared none.

\section{REFERENCES}

[1] Medzhitov R. Recognition of microorganisms and activation of the immune response. Nature 2007; 449(7164): 819-26.

[2] Arnett E, Seveau S. The multifaceted activities of mammalian defensins. Curr Pharm Des 2011; 17(38): 4254-69.

[3] Tosi MF. Innate immune responses to infection. J Allergy Clin Immunol 2005; 116(2): 241-9; quiz 250.

[4] Esche C, Stellato C, Beck LA. Chemokines: key players in innate and adaptive immunity. J Invest Dermatol 2005; 125(4): 615-28.

[5] Steinstraesser L, Kraneburg U, Jacobsen F, et al. Host defense peptides and their antimicrobial-immunomodulatory duality. Immunobiology 2011; 216(3): 322-33.

[6] Böhnke M, Masters BR. Confocal microscopy of the cornea. Prog Retin Eye Res 1999; 18(5): 553-628.

[7] DelMonte DW, Kim T. Anatomy and physiology of the cornea. J Cataract Refract Surg 2011; 37(3): 588-98.

[8] Calossi A. Corneal asphericity and spherical aberration. J Refract Surg 2007; 23(5): 505-14.

[9] Müller LJ, Pels E, Vrensen GF. The specific architecture of the anterior stroma accounts for maintenance of corneal curvature. Br J Ophthalmol 2001; 85(4): 437-43.

[10] Abdelkader H, Patel DV, McGhee CNJ, et al. New therapeutic approaches in the treatment of diabetic keratopathy: a review. Clin Exp Ophthalmol 2011; 39(3): 259-70.

[11] Göbbels M, Spitznas M, Oldendoerp J. Impairment of corneal epithelial barrier function in diabetics. Graefes Arch Clin Exp Ophthalmol 1989; 227(2): 142-4.

[12] Farjo A, McDermott M, Soong HK. Corneal anatomy, physiology, and wound healing. In: Yanoff M, Duker JS, Eds. Ophthalmology, 3rd ed. MO, Mosby: St. Louis 2008; pp. 203-8.

[13] Kinoshita S, Adachi W, Sotozono C, et al. Characteristics of the human ocular surface epithelium. Prog Retin Eye Res 2001; 20(5): 639-73.

[14] Ma DH, Chen JK, Zhang F, et al. Regulation of corneal angiogenesis in limbal stem cell deficiency. Prog Retin Eye Res 2006; 25(6): 563-90

[15] Wiley L, SundarRaj N, Sun TT, et al. Regional heterogeneity in human corneal and limbal epithelia: an immunohistochemical evaluation. Invest Ophthalmol Vis Sci 1991; 32(3): 594-602.

[16] Müller LJ, Pels L, Vrensen GF. Novel aspects of the ultrastructural organization of human corneal keratocytes. Invest Ophthalmol Vis Sci 1995; 36(13): 2557-67.

[17] Fini ME, Stramer BM. How the cornea heals: cornea-specific repair mechanisms affecting surgical outcomes. Cornea 2005; 24(8 Suppl): S2-S11.

[18] Müller LJ, Pels L, Vrensen GF. Ultrastructural organization of human corneal nerves. Invest Ophthalmol Vis Sci 1996; 37(4): 476-88.

[19] Ollivier FJ, Gilger BC, Barrie KP, et al. Proteinases of the cornea and preocular tear film. Vet Ophthalmol 2007; 10(4): 199-206.

[20] Wilson SE, Liu JJ, Mohan RR. Stromal-epithelial interactions in the cornea. Prog Retin Eye Res 1999; 18(3): 293-309.

[21] Dua HS, Faraj LA, Said DG, et al. Human Corneal Anatomy Redefined: a novel pre-Descemet's layer (Dua's layer). Ophthalmology 2013; 120(9): 1778-85.

[22] Joyce NC. Proliferative capacity of corneal endothelial cells. Exp Eye Res 2012; 95(1): 16-23.

[23] Stiemke MM, Edelhauser HF, Geroski DH. The developing corneal endothelium: correlation of morphology, hydration and $\mathrm{Na} / \mathrm{K}$ ATPase pump site density. Curr Eye Res 1991; 10(2): 145-56.

[24] Mergler S, Pleyer U. The human corneal endothelium: new insights into electrophysiology and ion channels. Prog Retin Eye Res 2007; 26(4): 359-78. 
[25] Bonanno JA. Identity and regulation of ion transport mechanisms in the corneal endothelium. Prog Retin Eye Res 2003; 22(1): 69-94.

[26] Joyce NC. Proliferative capacity of corneal endothelial cells. Exp Eye Res 2012; 95(1): 16-23.

[27] Griffith M, Osborne R, Munger R, et al. Functional human corneal equivalents constructed from cell lines. Science 1999; 10: 286(5447): 2169-72.

[28] Geroski DH, Matsuda M, Yee RW, et al. Pump function of the human corneal endothelium; effects of age and cornea guttata. Ophthalmology 1985; 92(6): 759-63.

[29] Srinivas SP. Cell signaling in regulation of the barrier integrity of the corneal endothelium. Exp Eye Res 2012; 95(1): 8-15.

[30] Watsky MA, McDermott ML, Edelhauser HF. In vitro corneal endothelial permeability in rabbit and human: the effects of age, cataract surgery and diabetes. Exp Eye Res 1989; 49(5): 751-67.

[31] Verkman AS, Ruiz-Ederra J, Levin MH. Functions of aquaporins in the eye. Prog Retin Eye Res 2008; 27(4): 420-33.

[32] Govindarajan B, Gipson IK. Membrane-tethered mucins have multiple functions on the ocular surface. Exp Eye Res 2010; 90(6): 655-63.

[33] Holly FJ, Lemp MA. Tear physiology and dry eyes. Surv Ophthalmol 1977; 22(2): 69-87.

[34] Wizert A, Iskander DR, Cwiklik L. Organization of lipids in the tear film: a molecular-level view. PLoS One 2014; 9(3): e92461.

[35] Dwivedi M, Backers H, Harishchandra RK, Galla HJ. Biophysical investigations of the structure and function of the tear fluid lipid layer and the effect of ectoine. Part A: Natural meibomian lipid films. Biochim Biophys Acta 2014; 1838(10): 2708-15.

[36] Ramamoorthy P, Nichols JJ. Mucins in contact lens wear and dry eye. Optom Vis Sci 2008; 85(8): 631-42.

[37] Snyder C, Fullard RJ. Clinical profiles of non dry eye patients and correlations with tear protein levels. Int Ophthalmol 1991; 15(6): 383-9.

[38] Saijyothi AV, Angayarkanni N, Syama C, et al. Two dimensional electrophoretic analysis of human tears: collection method in dry eye syndrome. Electrophoresis 2010; 31(20): 3420-7.

[39] Sariri R, Ghafoori H. Tear proteins in health, disease, and con tact lens wear. Biochemistry 2008; 73(4): 381-92.

[40] Bron AJ, Tiffany JM. Gouveia SM, et al. Functional aspects of the tear film lipid layer. Exp Eye Res 2004; 78(3): 347-60.

[41] McCulley JP, Shine WE. The lipid layer of tears: dependent on meibomian gland function. Exp Eye Res 2004; 78(3): 361-5.

[42] Gaffney EA, Tiffany JM, Yokoi N, et al. A mass and solute balance model for tear volume and osmolarity in the normal and the dry eye. Prog Retin Eye Res 2010; 29(1): 59-78.

[43] Dartt DA. Interaction of EGF family growth factors and neurotransmitters in regulating lacrimal gland secretion. Exp Eye Res 2004; 78(3): 337-45.

[44] Janssen PT, van Bijsterveld OP. Origin and biosynthesis of human tear proteins. Inv Ophthal Vis Sci 1983; 24(5): 623-30.

[45] Johnson ME, Murphy PJ. Changes in the tear film and ocular surface from dry eye syndrome. Prog Retin Eye Res 2004; 23(4): 449-74.

[46] Flower DR. The lipocalin protein family: structure and function. Biochem J 1996; 15; 318( Pt 1): 1-14.

[47] Spurr-Michaud S, Argüeso P, Gipson I. Assay of mucins in human tear fluid. Exp Eye Res 2007; 84(5): 939-50.

[48] Gipson IK, Yankauckas M, Spurr-Michaud SJ, et al. Characteristics of a glycoprotein in the ocular surface glycocalyx. Invest Ophthalmol Vis Sci 1992; 33(1): 218-27

[49] McKenzie RW, Jumblatt JE, Jumblatt MM. Quantification of MUC2 and MUC5AC transcripts in human conjunctiva. Invest Ophthalmol Vis Sci 2000; 41(3): 703-8.

[50] Argüeso P, Gipson IK. Epithelial mucins of the ocular surface: structure, biosynthesis and function. Exp Eye Res 2001; 73(3): 281-9.

[51] Guzman-Aranguez A, Argüeso P. Structure and biological roles of mucin-type O-glycans at the ocular surface. Ocul Surf 2010; 8(1): 8-17.

[52] Barabino S, Chen Y, Chauhan S, et al. Ocular surface immunity: Homeostatic mechanisms and their disruption in dry eye disease. Prog Retin Eye Res 2012; 31(3): 271-85.

[53] Akpek EK, Gottsch JD. Immune defense at the ocular surface. Eye 2003; 17(8): 949-56

[54] Kumar A, Yu SF. Toll-like receptors and corneal innate immunity. Curr Mol Med 2006; 6(3): 327-37.
[55] Mun JJ, Tam C, Evans DJ, et al. Modulation of epithelial immunity by mucosal fluid. Sci Rep 2011; 1(8): 1-7.

[56] Mantelli F, Argüeso P. Functions of ocular surface mucins in health and disease. Curr Opin Allergy Clin Immunol 2008; 8(5): 477-83.

[57] Lambiase A, Micera A, Sacchetti M, et al. Toll-like receptors in ocular surface diseases: overview and new findings. Clin Sci 2011; 120(10): 441-50.

[58] Zhang D, Zhang G, Hayden MS, et al. A toll-like receptor that prevents infection by uropathogenic bacteria. Science 2004; 303(5663): 1522-6

[59] Takeda K, Kaisho T, Akira S. Toll-like receptors. Annu Rev Immunol 2003; 21: 335-76.

[60] Tabeta K, Georgel P, Janssen E, et al. Toll-like receptors 9 and 3 as essential components of innate immune defense against mouse cytomegalovirus infection. Proc Natl Acad Sci USA 2004;101(10): 3516-21

[61] Medzhitov R. Toll-like receptors and innate immunity. Nat Rev Immunol 2001; 1(2): 135-45.

[62] Redfern RL, McDermott AM. Toll-like receptors in ocular surface disease. Exp Eye Res 2010; 90(6): 679-87.

[63] Imler JL, Hoffmann JA. Toll receptors in innate immunity. Trends Cell Biol 2001; 11(7): 304-11.

[64] Kumar A, Zhang J, Yu FS. Innate immune response of corneal epithelial cells to Staphylococcus aureus infection: role of peptidoglycan in stimulating proinflammatory cytokine secretion. Invest Ophthalmol Vis Sci 2004; 45(10): 3513-22.

[65] Wright SD, Ramos RA, Tobias PS, et al. CD14, a receptor for complexes of lipopolysaccharide (LPS) and LPS binding protein. Science 1990; 249(4975): 1431-3.

[66] Abreu MT, Vora P, Faure E, et al. Decreased expression of Tolllike receptor-4 and MD-2 correlates with intestinal epithelial cell protection against dysregulated proinflammatory gene expression in response to bacterial lipopolysaccharide. J Immunol 2001; 167(3): 1609-16.

[67] Li Q, Kumar A, Gui JF, et al. Staphylococcus aureus lipoproteins trigger human corneal epithelial innate response through toll-like receptor-2. Microb Pathog 2008; 44(5): 426-34.

[68] Li J, Shen J, Beuerman RW. Expression of toll-like receptors in human limbal and conjunctival epithelial cells. Mol Vis 2007; 13 : 813-22.

[69] Garfias $\mathrm{Y}$, Linares $\mathrm{M}$, Suárez $\mathrm{R}$, et al. Immunological characteristics of limbal epithelial cells: in vitro analysis of TLR4 function. Arch Soc Esp Oftalmol 2007; 82(2): 95-101.

[70] Zhang J, Wu XY, Yu FS. Inflammatory responses of corneal epithelial cells to pseudomonas aeruginosa infection. Curr Eye Res 2005; 30(7): 527-34

[71] Tallant T, Deb A, Kar N, et al. Flagellin acting via TLR5 is the major activator of key signaling pathways leading to NF-kappa B and proinflammatory gene program activation in intestinal epithelial cells. BMC Microbiol 2004; 4: 33.

[72] Gewirtz AT, Navas TA, Lyons S, et al. Cutting edge: bacterial flagellin activates basolaterally expressed TLR5 to induce epithelial proinflammatory gene expression. J Immunol 2001; 167(4): 1882-5.

[73] Kumar A, Zhang J, Yu FS. Toll-like receptor 3 agonist poly(I:C)induced antiviral response in human corneal epithelial cells. Immunology 2006; 117(1): 11-21.

[74] Ueta M, Hamuro J, Kiyono H, et al. Triggering of TLR3 by polyI:C in human corneal epithelial cells to induce inflammatory cytokines. Biochem Biophys Res Commun 2005; 331(1): 285-94.

[75] Lund JM, Alexopoulou L, Sato A, et al. Recognition of singlestranded RNA viruses by Toll-like receptor 7. Proc Natl Acad Sci USA 2004; 101(15): 5598-603.

[76] Hemmi H, Takeuchi O, Kawai T, et al. A Toll-like receptor recognizes bacterial DNA. Nature 2000; 408(6813): 740-5.

[77] Jiménez-Martínez MC, Mejía H, Linares M, et al. Expression of B7 molecules and TLR-9 on corneal epithelial cells infected with adenovirus: clinico-pathological implications in viral keratoconjunctivitis. Arch Soc EspOftalmol 2006; 81(7): 391-400.

[78] Pearlman E, Johnson A, Adhikary G, et al. Toll-like receptors at the ocular surface. Ocul Surf 2008; 6(3): 108-16.

[79] Beutler B. Inferences, questions and possibilities in toll-like receptor signalling. Nature 2004; 430(6996): 257-63.

[80] Yamamoto M, Sato S, Hemmi H, et al. Essential role for TIRAP in activation of the signalling cascade shared by TLR2 and TLR4. Nature 2002; 420(6913): 324-9. 
[81] Horng T, Barton GM, Flavell RA, et al. The adaptor molecule TIRAP provides signalling specificity for Toll-like receptors. Nature 2002; 420(6913): 329-33.

[82] Yamamoto M, Sato S, Hemmi H, et al. Role of adaptor TRIF in the MyD88- independent toll-like receptor signaling pathway. Science 2003; 301(5633): 640-3.

[83] Yamamoto M, Sato $\mathrm{S}$, Hemmi $\mathrm{H}$, et al. TRAM is specifically involved in the Toll-like receptor 4-mediated MyD88-independent signaling pathway. Nat Immunol 2003; 4(11): 1144-50.

[84] Burns K, Martinon F, Esslinger C, et al. MyD88, an adapter protein involved in interleukin-1 signaling. J Biol Chem 1998; 273(20): 12203-9.

[85] Akira S, Takeda K, Kaisho T. Toll-like receptors: critical proteins linking innate and acquired immunity. Nat Immunol 2001; 2(8): 675-80.

[86] Song HY, Régnier CH, Kirschning CJ, et al. Tumor necrosis factor (TNF)-mediated kinase cascades: bifurcation of nuclear factorkappaB and c-jun N-terminal kinase (JNK/SAPK) pathways at TNF receptor-associated factor 2. Proc Natl Acad Sci USA 1997; 94(18): 9792-6

[87] Beutler B. Innate immunity: an overview. Mol Immunol 2004; 40(12): 845-59.
[88] Ueta M, Kinoshita S. Innate immunity of the ocular surface. Brain Res Bull 2010; 81(2-3): 219-28.

[89] Dieu MC, Vanbervliet B, Vicari A, et al. Selective recruitment of immature and mature dendritic cells by distinct chemokines expressed in different anatomic sites. J Exp Med 1998; 88(2): 37386.

[90] Huang Q, Liu D, Majewski P, et al. The plasticity of dendritic cell responses to pathogens and their components. Science 2001; 294(5543): 870-5.

[91] Küchle M, Cursiefen C, Nguyen NX, et al. Risk factors for corneal allograft rejection: intermediate results of a prospective normal-risk keratoplasty study. Graefes Arch Clin Exp Ophthalmol 2002; 240(7): 580-4.

[92] Masli S, Turpie B, Hecker KH, et al. Expression of thrombospondin in TGFbeta-treated APCs and its relevance to their immune deviation-promoting properties. J Immunol 2002; 68(5): 2264-73.

[93] Vega JL, Keino H, Masli S. Surgical denervation of ocular sympathetic afferents decreases local transforming growth factorbeta and abolishes immune privilege. Am J Pathol 2009; 175(3): 1218-25.

[94] Taylor AW, Yee DG. Somatostatin is an immunosuppressive factor in aqueous humor. Invest Ophthalmol Vis Sci 2003; 44(6): 2644-9. 